\title{
The Importance of Reformation of Ukrainian Medical Higher Education
}

\author{
Kamilla Mahrlamova \\ Dnipro State Medical University
}

\author{
Roman Razumnyi \\ Dnipro State Medical University
}

Igor Shponka

Dnipro State Medical University

Svitlana Shandruk

Volodymyr Vynnychenko Central Ukrainian State Pedagogical University

\author{
Lina Smirnova \\ Volodymyr Vynnychenko Central Ukrainian State Pedagogical University
}

\begin{abstract}
Nowadays Ukrainian healthcare system is in search of ways to overcome the crisis and trying to build a new model which is close to world standards. Such kind of process requires a change in the paradigm of general basic secondary education and higher medical education. So, in the context of rapid development the issue of reforming the medical industry is urgent. It represents innovative technologies and evidencebased medicines, the introduction of new methods of treatment and diagnosis of diseases, the latest information, and modern medical technologies which could be turned into practice. In the context of globalization, the necessity to integrate the Ukrainian system of medical education requires studying the foreign experience of professional training of future doctors in the leading institutions in the world. In particular, the main way to become more professionally competent is the improvement and development of the level of Medical English in preparation of medical students and postgraduate students in Medicine.
\end{abstract}

Keywords: medical English, soft skills, collaborative learning, critical thinking, creativity

\section{INTRODUCTION}

Longlife medical education needs always to be renewed and improved in two ways, firstly, it is the quality, content, curriculum, authentical textbooks, journals and secondly the implementation of innovative psycho-pedagogical systems of education, interactive methods and approaches with the consideration of professional and personal development of the future doctor. That is why the personal development of future doctors needs to take into account and realization of the main innovative psycho-pedagogical techniques 
that give increasingly raise the effectiveness of the psychological and personal system of a future doctor (Arslan, 2020; Berzina, 2019).

The general preparatory course of study in a higher medical educational institution of the future doctor, in particular, the future family doctor consists of the acquisition of different kinds of subjects such as humanities, socio-economic, natural science, professional, and practical training cycles. At the same time, our modern world needs a new kind of worker, an up-to-date worker, a digital worker who would have not only usual medical knowledge and skills, in addition, to have intelligent professional thinking and strong soft skills. This process is more complicated and requires lots of inner motivation and lies deeper which starts from secondary school and continues in the medical higher institution transforms into the process of postgraduate study, which means lifelong education (Senyuta, 2020; Sitsinska et al., 2021). A doctor`s profession is unique, it combines many characteristics such as self-development, a huge amount of practical work, ability to medical skills, being knowledgeable of the prospects of the standard, and innovative medical education and industry in general (Waiel and Talat, 2020; Zub et al., 2021).

Modern medical education and future doctors should have highly professional theoretical and practical training, they should know new methods of prevention diseases, early diagnosis, and high-tech therapy of diseases. The main interest lies in the experience of medical education in foreign countries. Higher education in Ukraine exists and develops in the environment of national higher education systems of Great Britain, Poland, Germany, Russia, France, and other countries (Petersen et al., 2018). However, it is worth saying, that for us the main important experience is the experience of Great Britain because of this country`s

native historical experience, strategies, new approaches, and techniques. Great Britain is the centre of innovation, a birth of great medical experience. British higher education system, as well as some other European countries, is inherited the diversification of the education system at the same time they provide the traditional standard higher education alongside the new one with the emerging types of education in particular open universities, colleges, centres of distance learning, part-time courses (Palchuk, 2011).

We rely on the experience and practice of Great Britain medical education. Most European countries show high requirements in language knowledge at the beginning of their study, in the process of entering the University. Each applicant should have a level of English B2/C1 and these levels are accepted all over the world as the European standards for grading the level of English proficiency. The Common European Framework of Reference for Languages: Learning, Teaching, Assessment (Council of Europe, 2001), abbreviated in English as CEFR, CEF or CEFRL, is a guideline used to describe the achievements of learners of foreign languages across Europe and, increasingly, in other countries. The CEFR is also intended to make it easier for educational institutions and employers to evaluate the language qualifications of candidates for education admission or employment. B2 means that an independent learner can understand the main ideas of complex text on both concrete and abstract topics, including technical discussions in their field of specialization; interact with a degree of fluency and spontaneity that makes regular interaction with native speakers quite possible without strain for either party; produce clear, detailed text on a wide range of subjects and explain a viewpoint on a topical issue giving the advantages and disadvantages of various options. $\mathrm{C} 1$ means that the user is proficient and can understand a wide range of demanding, longer clauses, and recognize implicit meaning; express ideas fluently and spontaneously without much obvious searching for expressions; use language flexibly and effectively for social, academic, and professional purposes; produce clear, well-structured, detailed text on complex subjects, showing controlled use of organizational patterns, connectors, and cohesive devices (Luzik et al., 2021).

This paper aims at examining the question of how to modernize Ukrainian medical education with the implementation of foreign experience and what are the main features of a modern doctor. The research methods include analysis, generalization, and the systemic approach, they are most appropriate for answering the questions of the importance of reformation of Ukrainian medical higher education.

\section{MATERIALS AND METHODS}

The document "The state medical education and practice of the UK" (2020) provides information that the pandemic has been a defining experience for the medical profession and it continues to shape doctor's 
professional and personal lives. To improve the quality of education thousands of medical teachers and students hold medical educational training and webinars all over the world. Medical schools equip students with the scientific background and technical skills they need for practice. But, just as importantly, they must enable new graduates to both understand and commit to high personal and professional values. Medicine involves personal interaction with people, as well as the application of science and technical skills. Today's undergraduates - tomorrow's doctors - will see huge changes in medical practice. There will be continuing developments in biomedical sciences and clinical practice, new health priorities, rising expectations among patients and the public, and changing societal attitudes (Tafani, 2021). Basic knowledge and skills, while fundamentally important, will not be enough on their own. Medical students must be inspired to learn about medicine in all its aspects to serve patients and become the doctors of the future. With that perspective and commitment, allied to the specific knowledge, skills and behaviours set out in Tomorrow's Doctors and Good medical practice, they will be well placed to provide and to improve the health and care of patients, as scholars and scientists, practitioners and professionals (Tomorrow's Doctors, 2009; Kovalenko and Kytaika, 2021).

It is high time to prepare future doctors with the right strong level of English language such as B1/B2 of the Common European Framework of Reference for Languages (CEFRL). And such kind of education and preparation is carried out in DMU (State Establishment Dnipro Medical University of Health Ministry of Ukraine). English is the international language of science in general, in particular, medical language for example in international medical forums, and on the internet, you can find lots of medical data and information. New researches and investigations could be found in foreign journals, and with the right level of English, graduates could be knowledgeable in new ways of education and have a great opportunity to be properly educated.

This education is carried out through the syllabus and the curriculum and was approved by the scientific council of the university. The program was designed by the department of language preparation, State Establishment Dnipro Medical University of Health Ministry of Ukraine and include a course "Medical English for medical students and Ph.D. postgraduate students". The purpose of the course is to develop soft skills such as collaborative learning, critical thinking these skills improve the quality of future doctors training in accordance with the world and European standards to strengthen the competitiveness of Ukrainian higher medical education and the ability to optimize the conditions for international mobility.

This course is one of the main ways for our medical students and postgraduate students to study and use medical English in their scientific researches and have further scientific growth. The combined working group of 84 postgraduate students was divided into 6 groups of students. Only new approaches and techniques were used on these groups to build real scientists with their own thoughts for medical collaborative work and learning. This course has been used to show the results in medical English achievement with the higher level, higher self-esteem, higher motivation.

\section{RESULTS AND DISCUSSION}

Each subject in the process of preparation of a future doctor should contain, four main qualities such as:

- critical thinking (the process of thinking carefully about a subject or idea, without allowing feelings or opinions to affect you);

- creativity (the ability to produce original and unusual ideas or to make something new or imaginative);

- collaboration (the situation of two or more people working together to create or achieve the same thing);

- communication (the process of sharing information, especially when this increases understanding between people or groups).

And especially when we speak about a doctor of the $21^{\text {st }}$ century and the situation of the pandemic which put huge pressure on a doctor itself and the medical higher education in general. That is why only 
doctors who have medical critical thinking, medical creativity, medical collaboration, medical professional communication could work in these challenging conditions (Grabar and Grabar, 2020; Skydan et al., 2020). It is not possible to respond to the fast-changing modern medical field with average standardized competence.

To suit the purpose of the research, our interactive B2 Medical English course was implemented in every medical English lesson in the first course of different specialities and faculties such as the I and II medical faculties, I and II international faculties, and stomatology department. At the beginning of the course, it was challenging to realize the idea and we face the problem of acquiring new techniques and approaches then medical students continuously realized the idea and worked very hard to achieve the purpose in a very active and thoughtful way. They had to integrate new material, and English with the way of using four main qualities such as critical thinking, creativity, collaboration, communication in medical themes. After a year of studying, medical students and teachers who taught this subject had a survey which was conducted at Dnipro Medical University, this survey show the attitude of teachers and students to the new course and the necessity of it in the educational process. Almost all students and postgraduate students were participating in the new course of medical English with lots of engagement. It was their wish and desire to improve their English medical skills and knowledge. At the beginning of the study, about $97 \%$ of students were actively and purposefully engaged in the process of study half of the year, then in 4 months $87 \%$ of students still were interested in gaining new knowledge. About $80 \%$ showed active use of main qualities like critical thinking, creativity, collaboration, communication. $60 \%$ of students participated in additional activities like speaking club with the investigation of medical cases. The trial implementation of the new way of interaction between teachers and students took 10 months and approximately $50 \%$ of the students spend 3-4 hours a week, 30\% of students spend 5 hours weekly. Day-to-day work gives definite change and four out of five future doctors (81\%) described that the level of proficient knowledge in English is changing very rapidly and they call it "a significant change". The teachers' staff devoted that students had lots of own new ideas which help them to deal with new material, and the usage of authentic materials like medical journals made students more engage and motivated because they feel how their knowledge little by little growing and they can cope with lots of new medical authentic materials.

This research took into account the results of scientific studies of S.K. Lope (2016), R. Paul (2015), B.J. Thayer-Bacon (2017), L. White (2017), who were interested in the study of the problem of the development of medical critical thinking.

Medical critical thinking is a purposeful, self-controlled, assessment and feedback of the situation. The main principles of critical thinking are observation, interpretation, analysis, conclusion, providing an assessment of the situations (Paul, 2015).

Medical creativity is based on high intellectual ability and original critical thinking of solving medical cases. It means to shift from standard basic knowledge and skills to an entirely new interactive form of thinking and usage of new techniques and approaches.

Medical collaboration in health care is defined as healthcare professionals assuming complementary roles and cooperatively working together, sharing responsibility for problem-solving and making decisions to formulate and carry out plans for patient care (Fagin, 1992; Baggs \& Schmitt, 1988; Vasenko et al., 2020). Collaboration between physicians, nurses, and other healthcare professionals increases team members' awareness of each others' types of knowledge and skills, leading to self-development and professional improvement in decision making (Christensen \& Larson, 1993). Medical work is teamwork, especially in pandemic just only in teamwork, doctors can provide an effective and efficient way of treating a disease. Team working and sharing of knowledge and expertise were positively affected in the period of a pandemic. $62 \%$ felt teamwork between doctors had been affected for the better. $48 \%$ of doctors felt the same across healthcare professionals. Only $7 \%$ of doctors felt there had been a negative impact on teamwork. As well as $52 \%$ saw a positive impact on sharing knowledge and experience across medical education and profession in general (The state of medical education..., 2020).

Medical professional communication is the development and production of materials that deal specifically with medicine or health care. As usual, they are professional medical communicators who write, edit or develop materials about medicine and health. Good medical communication skills are essential for 
a future doctor. And the main thing is that the doctor has to completely understand his patients, this helps him to recognize the problems and make an accurate diagnosis. And of course, a high level of English helps to avoid fatal medical errors (Chiu, 2019; Ortega-Abente and Ruiz-Flores, 2021).

Modern doctors have to combine hard skills and soft skills. In authors opinion, additional attention could be paid to HR (Human Resources) such as talent searching, personnel training and, development, HR planning, team structuring. It is very important to introduce a family doctor with the main general ideas (it could be for example additional course). This subject in the field of medical purposes could bring lots of advantages in promotion of medical knowledge, healthy lifestyle, ways of preventing diseases, and the ways of effective treatment. At the same time to ensure and guarantee the quality of diverse medical education, it is necessary to introduce the management skills such as team management, risk assessment, public performance. One of the researchers told that family doctors should be from one side a clinical worker from the other side a manager in their everyday work and they should do all their work with innovation and invention with the usage of medical critical thinking, medical creativity, medical collaboration, medical professional communication (Jha et al., 2015).

\section{CONCLUSIONS}

To sum up, it is worth saying that in the new social situation, Ukrainian higher medical education is undergoing significant changes in our modern world against the background of globalization and democratization of society and the formation of an open market economy, humanization, and informatization of all aspects of society. In the present study, the authors wanted to show the importance of implementation of the experience of development of higher medical education from foreign countries into Ukrainian. The crucial thing in this process is acquiring a strong level of professional medical English. Medical terminology is not enough. If you're a medical professional in an English-speaking country (or communicating with an international audience), you also need to know how to speak with patients and coworkers. Professional colleagues may need more detailed, technical explanations and all these explanations have to be written in English. It's important to consider your audience. That is why medical professionals couldn't be in the modern labour market without language knowledge. This requirement involves creating meaningful learning experiences of other countries and implementing them in the Ukrainian medical system. So to determine priorities of higher medical education the experts are considering the necessity of providing professional knowledge, skills, abilities on modern scientific level of the most important sections of medicine; to increase the competence, self-improvement in the chosen speciality; create conditions for personal growth and development of the doctor's creative personality. The suggested course helps to keep pace with the time and correspond with new requirements of the labour market and medical educational system where acquisition of medical English plays a vital role.

\section{REFERENCES}

Arslan, N. (2020). Positive values and educational stress in adolescents. International Journal of Learning and Change, 12(3), 325-332.

Baggs, J.G., \& Schmitt, M.H. (1988). Collaboration Between Nurses and Physicians. Image: The Journal of Nursing Scholarship, 20(3), 145-149.

Berzinina, D. (2019). Learning by doing. case study: Education for sustainable development at the university of latvia. Periodicals of Engineering and Natural Sciences, 7(1), 156-164.

Chiu, J.S. (2019). Better education and training in apologies to resolve medical mishaps disputes. Medicine and Law, 38(1), 59-72.

Christensen, C., \& Larson, J.R. (1993). Collaborative Medical Decision Making. Medical Decision Making, 13(4), 339-346.

Council of Europe. (2001). Common European Framework of Reference for Languages: Learning, Teaching, Assessment. Retrieved from http://assets.cambridge.org/052180/3136/sample/0521803136ws.pdf 
Fagin, C.M. (1992). Collaboration Between Nurses and Physicians: No Longer a Choice. Academic Medicine, 67(5), 295-303.

General Medical Council. (2020). The state of medical education and practice in the UK. Retrieved from https://www.gmc-uk.org/about/what-we-do-and-why/data-and-research/the-state-of-medicaleducation-and-practice-in-the-uk

General Medical Cpuncil. (2009). Tomorrow's Doctors. Outcomes and standards for undergraduate medical education. Retrieved from https:/www.kcl.ac.uk/lsm/study/outreach/downloads/tomorrows-doctors.pdf

Grabar, I., \& Grabar, O. (2020). Modeling of the limit states in the dynamic systems of living and lifeless nature. Scientific Horizons, 3(88), 59-73.

Jha, V., Mclean, M., Gibbs, T.J., \& Sandars, J. (2015). Medical Professionalism Across Cultures: A Challenge for Medicine and Medical Education. Medical Teacher, 37(1), 74-80.

Kovalenko, R., \& Kytaika, O. (2021). The constitutional weakness of ukraine's health care reform. Medicine and Law, 40(1), 101-124.

Lope, S.K. (2016). Critical Thinking in Nursing: A Cognitive Skills Workbook. Philadelphia: Lippincott Williams \& Wilkins.

Luzik, E.V., Demchenko, N.I., Melnyk, N.I., Semichenko, V.A., \& Proskurka, N.M. (2021). Influence of tolerance to uncertainty on personal and professional development of pilots during aviation specialists' training. INCAS Bulletin, 13(Special Issue), 143-157.

Ortega-Abente, L., \& Ruiz-Flores, J. (2021). Psychological aspects as the components of academic mobility of medical workers. Scientific Bulletin of Mukachevo State University. Series "Pedagogy and Psychology", 7(2), 54-62.

Palchuk, M. (2011). Evolutionary Development of Professional Training of Production Staff in EU Countries: The Experience of the United Kingdom. Vyshcha Shkola, 2, 85-98.

Paul, R. (2015). Critical Thinking: Tools for Taking Charge of Your Professional and Personal Life. Upper Saddle River: FT Press.

Petersen, R., Grümmer, R., Jendrossek, V., Sauerwein, W., \& Schara, U. (2018). Mentoring in a medical faculty: A chance for organisational learning. International Journal of Learning and Change, 10(3), 198-219.

Senyuta, I.Y. (2020). Modern civilistic instruments of medical reform: Issues of law implementation and law enforcement. Journal of the National Academy of Legal Sciences of Ukraine, 27(3), 109-127.

Sitsinska, M., Sitsinskiy, A., Nikolaiev, V., Khadzhyradieva, S., \& Hasiuk, I. (2021). Legal and socioeconomic aspects of reforming ukraine's higher education system. Journal of the National Academy of Legal Sciences of Ukraine, 28(1), 88-98.

Skydan, O., Nykolyuk, O., Pyvovar, P., \& Topolnytskyi, P. (2020). Assessment of the social security level in the context of coronavirus contagion (COVID-19). Scientific Horizons, 6(91), 7-18.

Tafani, I. (2021). Health, well-being sustainability and rights in the time of covid-19 infection: Infection management by the albanian legal order. Rivista Di Studi Sulla Sostenibilita, (1), 133-149.

Thayer-Bacon, B.J. (2017). Transforming Critical Thinking: Thinking Constructively. New York: Teachers College Press.

Vasenko, O., Zinchenko, I., Tsytlishvili, K., \& Bikasov, V. (2020). Research of methods of inactivation of the antibiotic cyprofloxacin in order to prevent environmental pollution and protect human health. Scientific Horizons, 7(92), 19-25.

Waiel, K.M., \& Talat, A.G. (2020). The challenges facing innovation teams in healthcare organizations: A case study of king abdullah medical city. Periodicals of Engineering and Natural Sciences, 8(3), 1425-1437.

White, L. (2017). Critical Thinking in Practical/vocational Nursing. Boston: Cengage Learning.

Zub, L.O., Roborchuk, S.V., \& Buzdugan, I.O. (2021). Pedagogical theory and personality development during distance learning among medical university students. Scientific Bulletin of Mukachevo State University. Series "Pedagogy and Psychology”, 7(1), 54-62. 